\title{
On Attaching a Wire to a Triangulated Surface
}

\author{
N. J. Champagne, W. A. Johnson, D. R. Wilton
}

This article was submitted to Institute of Electrical and Electronics Engineers Antennas and Propagation Society Symposium, San Antonio, TX, June 16-21, 2002

\section{January 28, 2002}

U.S. Department of Energy

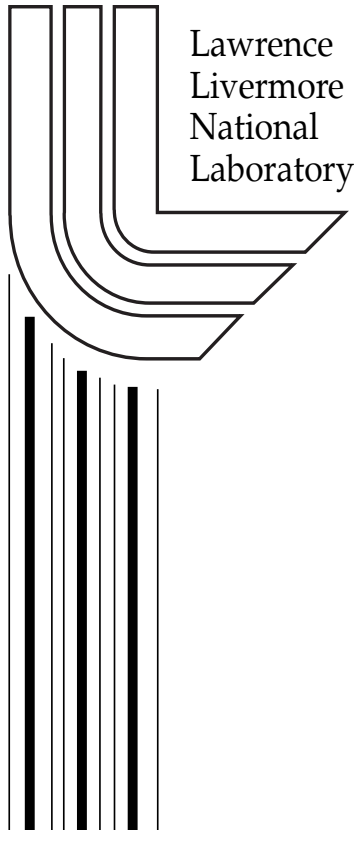




\section{DISCLAIMER}

This document was prepared as an account of work sponsored by an agency of the United States Government. Neither the United States Government nor the University of California nor any of their employees, makes any warranty, express or implied, or assumes any legal liability or responsibility for the accuracy, completeness, or usefulness of any information, apparatus, product, or process disclosed, or represents that its use would not infringe privately owned rights. Reference herein to any specific commercial product, process, or service by trade name, trademark, manufacturer, or otherwise, does not necessarily constitute or imply its endorsement, recommendation, or favoring by the United States Government or the University of California. The views and opinions of authors expressed herein do not necessarily state or reflect those of the United States Government or the University of California, and shall not be used for advertising or product endorsement purposes.

This is a preprint of a paper intended for publication in a journal or proceedings. Since changes may be made before publication, this preprint is made available with the understanding that it will not be cited or reproduced without the permission of the author.

This work was performed under the auspices of the United States Department of Energy by the University of California, Lawrence Livermore National Laboratory under contract No. W-7405-Eng-48.

This report has been reproduced directly from the best available copy.

Available electronically at http://www.doc.gov/bridge

Available for a processing fee to U.S. Department of Energy

And its contractors in paper from

U.S. Department of Energy

Office of Scientific and Technical Information

P.O. Box 62

Oak Ridge, TN 37831-0062

Telephone: (865) 576-8401

Facsimile: (865) 576-5728

E-mail: reports@adonis.osti.gov

Available for the sale to the public from

U.S. Department of Commerce

National Technical Information Service

5285 Port Royal Road

Springfield, VA 22161

Telephone: (800) 553-6847

Facsimile: (703) 605-6900

E-mail: orders@ntis.fedworld.gov

Online ordering: http://www.ntis.gov/ordering.htm

OR

Lawrence Livermore National Laboratory

Technical Information Department's Digital Library

http://www.llnl.gov/tid/Library.html 


\title{
On Attaching a Wire to a Triangulated Surface
}

\author{
Nathan J. Champagne* \\ Defense Sciences Engineering Division \\ Lawrence Livermore National Laboratory \\ Livermore, CA 94550 \\ William A. Johnson \\ Electromagnetics and Plasma Physics Analysis Department \\ Sandia National Laboratories \\ Albuquerque, NM 87185-1152 \\ Donald R. Wilton \\ Department of Electrical and Computer Engineering \\ University of Houston \\ Houston, TX 77204-4005
}

\section{Introduction}

There have been many papers that have focused on the attachment of wires to surfaces. The focus of this paper will be on wires connected to arbitrarily shaped surfaces, a body that may be modeled with triangles as described in [1]. The basis function for the wire-tosurface junction is constructed by building the $1 / r$ variation of the surface current near the junction into the surface current. In the following we summarize junction bases as currently used. In the presentation we consider their numerical implementation, examine alternative formulations, and review validation studies that prove the approach is robust with respect to wire orientation and surface geometry at the junction.

\section{Basis Function Formulation}

The parameters for the junction basis function are illustrated in Figure 1. The basis function for the $n$th junction on a structure, as proposed in [2], is given by

$$
\boldsymbol{\Lambda}_{n}^{J}(\mathbf{r})=\left\{\begin{array}{cc}
K_{n l}\left[1-\frac{\left(h_{n l}^{J+}\right)^{2}}{\left(\boldsymbol{\rho}^{+} \cdot \hat{\mathbf{h}}_{n l}^{J+}\right)^{2}}\right] \boldsymbol{\Lambda}_{n l}^{B}(\mathbf{r}), & \mathbf{r} \text { on } S_{n l}^{J+} \\
\boldsymbol{\Lambda}_{n}^{W}(\mathbf{r}), & \mathbf{r} \text { on } S_{n}^{J-} \\
0, & \text { otherwise }
\end{array}\right.
$$

where $S_{n l}^{J+}$ is the $l$ th triangle connected to the $n$th junction, and $S_{n}^{J-}$ is the wire connected to the $n$th junction. The basis functions $\boldsymbol{\Lambda}_{n l}^{B}(\mathbf{r})$ and $\boldsymbol{\Lambda}_{n}^{W}(\mathbf{r})$ are the body (surface) basis function [1], associated with the edge opposite the junction vertex, and the 
wire basis function [2], respectively. The height vector $\mathbf{h}_{n l}^{J+}$ of the triangle is directed from the junction vertex to the edge opposite the junction vertex. The quantity $\boldsymbol{\rho}^{+}$is the vector from $\mathbf{r}$ on $S_{n l}^{J+}$ to the junction vertex. The coefficient $K_{n l}$ is chosen as

$$
K_{n l}=\frac{\alpha_{n l}}{\ell_{n l} \sum_{l=1}^{N J n} \alpha_{n l}}=\frac{\alpha_{n l}}{\ell_{n l} \alpha_{n}^{t}}
$$

so that the total flux from the attached triangles into the wire is unity. Here, $\alpha_{n l}$ is the angle between the two edges of $S_{n l}^{J+}$ common to the junction vertex. The sum of these angles about the junction vertex is $\alpha_{n}^{t}$. The number of triangles attached to the junction is $N J n$, and the length of the edge opposite the junction vertex is $\ell_{n l}$. The surface divergence of (1) is given by

$$
\nabla_{S} \cdot \boldsymbol{\Lambda}_{n}^{J}(\mathbf{r})=\left\{\begin{array}{cc}
\frac{2 K_{n l}}{h_{n l}^{J+}}, & \mathbf{r} \text { on } S_{n l}^{J+} \\
-\frac{1}{h_{n}^{J-}}, & \mathbf{r} \text { on } S_{n l}^{J-} \\
0, & \text { otherwise. }
\end{array}\right.
$$

The surface current on the bodies is represented as

$$
\mathbf{J}(\mathbf{r}) \approx \sum_{n=1}^{N B} I_{n}^{B} \boldsymbol{\Lambda}_{n}^{B}(\mathbf{r})+\sum_{n=1}^{N J} I_{n}^{J} \boldsymbol{\Lambda}_{n}^{J}(\mathbf{r}), \quad \boldsymbol{r} \text { on } S_{B},
$$

and the axial current on the wires is given by

$$
\mathbf{I}(\mathbf{r}) \approx \sum_{n=1}^{N W} I_{n}^{W} \boldsymbol{\Lambda}_{n}^{W}(\mathbf{r})+\sum_{n=1}^{N J} I_{n}^{J} \boldsymbol{\Lambda}_{n}^{J}(\mathbf{r}), \quad \mathbf{r} \text { on } S_{W}
$$

where the total number of unknowns $(\mathrm{N})$ is equal to the number of surface current unknowns (NB) plus the number of wire current unknowns (NW) plus the number of junction current unknowns (NJ).

\section{Results}

The geometry for a wire inside a conducting box with two apertures is shown in Figure 2 [3]. The wire is excited by a $1 \mathrm{~V}$ source and is loaded at both ends with a $50 \Omega$ load. The normalized current at the wire end opposite the source is shown in Figure 3. The experimental results are from [3], and the numerical results are calculated using EIGER [4]. The data labeled as one region are obtained using the EFIE. The two-region results are calculated by using electric and magnetic currents in the aperture in addition to the EFIE. The interior and exterior regions are isolated by only allowing coupling through 
the aperture. Finally, the Green's function results are from using a periodic Green's function to mimic a cavity Green's function. All the numerical results show good agreement with the experimental data.

\section{Conclusion}

The junction basis function proposed in [2] is designed to model the surface current variation near a wire-to-surface junction, where the surface is composed of arbitrary collections of triangles. The results presented demonstrate that the junction basis function can provide accurate currents.

\section{Acknowledgments}

This work was performed under the auspices of the U.S. Department of Energy by the University of California, Lawrence Livermore National Laboratory under Contract W7405-Eng-48 and by Sandia National Laboratories, a multiprogram laboratory operated by Sandia Corporation, a Lockheed Martin Company, under contract No. DE-AC0494AL85000.

\section{References}

1. S. M. Rao, D. R. Wilton, and A. W. Glisson, "Electromagnetic scattering by surfaces of arbitrary shape," IEEE Trans. Antennas Propagat., vol. 30, no. 3, pp. 409-418, May 1982.

2. S. U. Hwu, D. R. Wilton, and S. M. Rao, "Electromagnetic scattering and radiation by arbitrary conducting wire/surface configurations," 1988 IEEE AP-S International Symposium Digest, Syracuse, New York, June 1988, pp. 890-893.

3. A. P. Duffy, T. M. Benson, and C. Christopoulos, "Propagation along a wire placed inside a cavity with an aperture: A comparison of measurements and transmissionline modeling (TLM)," IEEE Trans. Electromagn. Compat., vol. 36, no. 2, pp. 144 146, May 1994.

4. R. M. Sharpe, J. B. Grant, N. J. Champagne, W. A. Johnson, R. E. Jorgenson, D. R. Wilton, W. J. Brown, and J. W. Rockway, "EIGER: Electromagnetic Interactions GEneRalized," 1997 IEEE AP-S International Symposium and North American URSI Radio Science Meeting, Montreal, Canada, July 1997, pp. 1880-1883.

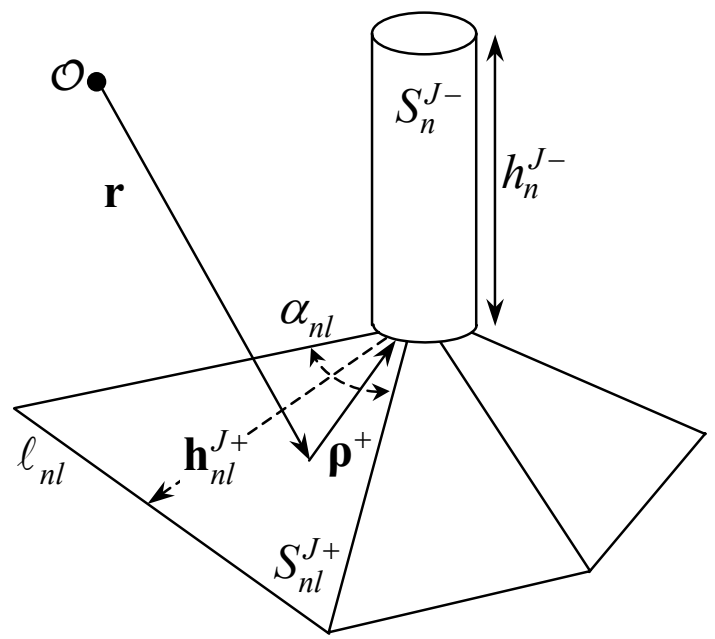

Figure 1. The wire-to-surface junction geometry and its associated parameters. 


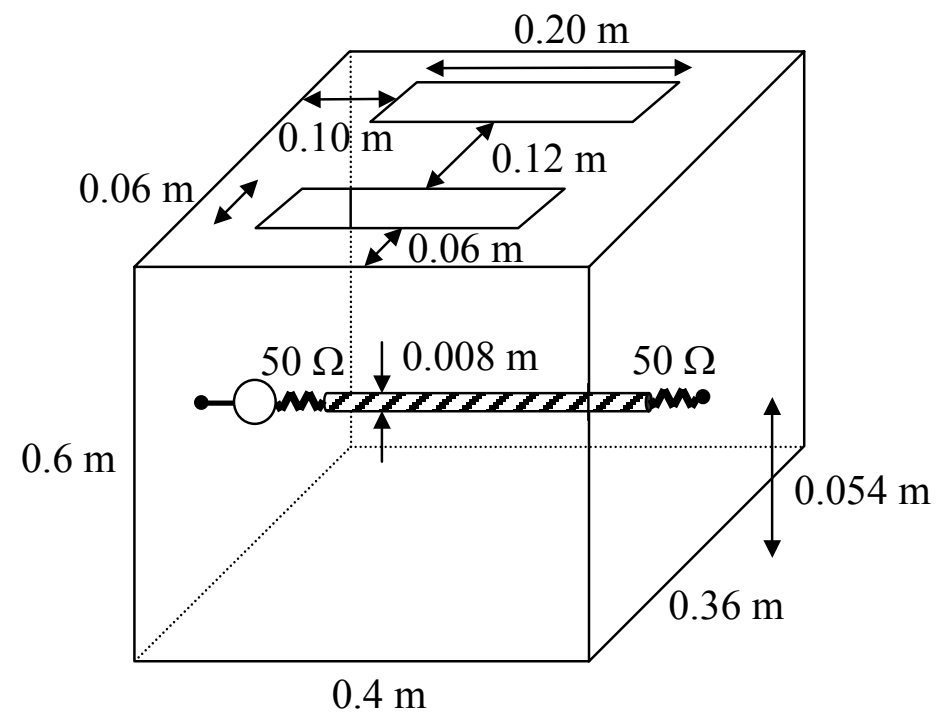

Figure 2. A conducting box with two apertures on the top and a wire with $50 \Omega$ loads terminating on the box walls.

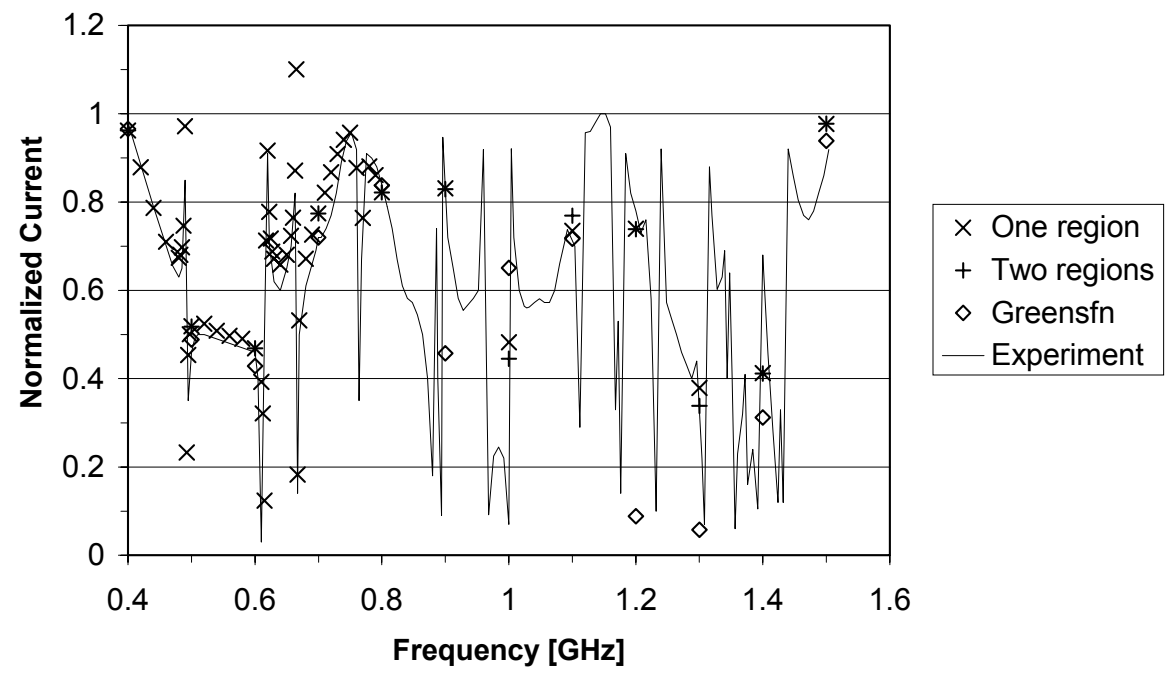

Figure 3. The current (normalized to $10 \mathrm{~mA}$ ) on the wire end without the excitation. 